\title{
GTPYS-STIMULATED HYDROLYSIS OF PHOSPHATIDYINOSITOL-4,5-BISPHOSPHATE BY SOLUBLE PHOSPHOLIPASE C FROM HUMAN PLATELETS REQUIRES SOLUBLE GTP-BINDING PROTEIN 1
}

Joseph J. Baldassare*, Michael A. Knipp*, Patricia A. Henderson* and Gary J. Fisher ${ }^{+}$

*American Red Cross, Bi-State Chapter, 4050 Lindell Blvd., St. Louis, Mo. 63108

tDepartment of Dermatology,

University of Michigan School of Medicine, Ann Arbor, MI 48109-0010

Received Apri1 27, 1988

Summary - GTP-binding activity was fractionated into two peaks (GI and GII) by chromatography on heparin-agarose. GTP-dependent PLC activity eluted as a single peak, which co-chromatographed with GTP-binding peak GII.

Rechromatography of peak GII on heparin-agarose, in the presence of $0.5 \%$ sodium cholate, resulted in separation of PLC and GTP-binding activities, and loss of GTP-dependent PLC activity. Recombining fractions containing PLC and GTP-binding activities restored GTP-dependent PLC activity. A specific GTPbinding protein of 29,000 daltons was jidentified in peak GII by Western blotting of column fractions with $\left[\alpha-{ }^{32}\right.$ P $]$ GTP. These results demonstrate that the soluble phospholipase $C$ from human platelets is regulated by GTP S-binding protein (G29). 1988 Academic Press, Inc.

Introduction - A guanine nucleotide binding protein has been implicated in coupling agonist to the phospholipase C-catalyzed hydrolysis of $\mathrm{PIP}_{2}$ in many cell types (1-3) including platelets $(4-8)$. Haslam and Davidson $(7,8)$ reported that GTP and its non-hydrolyzable analogs enhanced thrombin-induced diacylglycerol formation and secretion of 5-hydroxytryptamine when added to a suspension of electrically permeabilized platelets. platelets permeabilized by the addition of saponin gave virtually identical results (6). Baldassare and Fisher $(4,9)$ showed that thrombin and GTP S synergistically stimulated

1 This work was supported in part by National Red Cross funds. The cost of publication of this article were defrayed in part by payment of page charges. This article must therefore by marked "advertisement" in accordance with 18 U.S.C. Section 1734 solely to indicate this fact.

Abbreviations: The abbreviations used are: PIP $_{2}$, phosphatidylinositol 4,5bisphosphate; PI, phosphatidylinositol; PE, phosphatidylethanolamine; PS, phosphatidylserine; $\mathrm{IP}_{3}$, inositol 1,4,5-trisphosphate; EGTA, [ethylenebis (oxyethylene-nitrilo)] tetraacetic acid; GTPYS, guanosine 5'-(3-0-thio) triphosphate; SUV, small unilamellar vesicles. 
inositol phosphate release from $\left[{ }^{3} \mathrm{H}\right]$ inositol-labeled platelet membranes. Studies $(9,10)$ utilizing exogenous $\mathrm{PIP}_{2}$-containing lipid vesicles have demonstrated that GTP or GTPrS stimulate breakdown of $\mathrm{PIP}_{2}$ by platelet membranes.

The ability of GTP and non-hydrolyzable GTP analogs to stimulate hydrolysis of $\mathrm{PIP}_{2}$ from platelet membranes indicates that the membranes contain a guanine nucleotide dependent phospholipase $C$. However, the majority of PI-specific phospholipase $C$ activity in human platelets is recovered in the soluble fraction ( $100,000 \times \mathrm{g}$ supernatant). We (9) and Deckmyn et al. have shown that this cytosolic PI-specific phospholipase $C$ activity is also activated by GTPrS to specifically hydrolyze PIP 2 . Banno et al. (12) have also reported that breakdown of $\mathrm{PIP}_{2}$ by partially purified soluble phospholipase $C$ from human platelets was enhanced by GTP. These workers suggested that GTP has a direct effect on the phospholipase $C$.

In the present study, we demonstrate that stimulation by GTPrs of the soluble PI-specific PLC from platelets is mediated by GTP-binding protein(s). To do this, we have resolved soluble GTP-binding activity and soluble phospholipase $C$ activity by column chromatography in the presence of cholate.

Materials and Methods - [Inosiţ $\mathrm{Q}-2,3-{ }^{3} \mathrm{H}$ ]phosphatidylinositol 4,5bisphosphate, [ ${ }^{35}$ S]GTPrs and [ $\left.{ }^{2} \mathrm{P}\right]$ GTP were purchased from New England Nuclear (Boston, Mass.). Phosphatidylethanolamine and phosphatidylserine were purchased from Avanti Polar Lipids, Inc. (Birmingham, Alabama) and checked for purity on Silica Gel 60 plates (Merck) (13). All other chemicals were obtained from Sigma Chemical Company (St. Louis, Mo.).

Preparation of Platelet Cytosol: Platelet high speed supernantant was prepared by sonication of newly outdated human platelets. Phosphoinositide Hydrolysis - - PLC activity was assayed with small unilamellar vesicle as described previously (9). Free $\mathrm{Ca}^{2+}$ concentrations were adjusted with Ca ${ }^{2+} /$ EGTA as described by Raaflaub (9). Reactions were started by the addition of phospholipase $C$ and incubated at $37^{\circ} \mathrm{C}$ for 5 minutes. The reactions were terminated by the addition of $1 \mathrm{ml}$ of chloroform/methanol/1N HCl $(10 / 10 / .06)$ and centrifugation at $250 \times \mathrm{g}$ for 5 minutes.

GTPYS Binding Activity - Specific binding of $\left[{ }^{35} \mathrm{~S}\right]$ GTP $\gamma \mathrm{S}$ was measured as described by Northup et al. (15). Briefly, samples were incubated with $\left[{ }^{35} \mathrm{~S}\right]$ GTPYS $(0.3 \mathrm{uM})$ in buffer containing $20 \mathrm{mM}$ Tris-HCl, $1 \mathrm{mM}$ EDTA, $0.1 \mathrm{mM}$ dithiothreitol, $100 \mathrm{mM} \mathrm{NaCl}, 0.18$ lubrol PX, $2.5 \mathrm{mM} \mathrm{MgCl} 2$ for 1 hour at $30^{\circ} \mathrm{C}$. Bound nucleotide was separated from free by filtration through B85 nitrocellulose filters (S\&S; A. H. Thomas, Philadelphia, PA). Specific binding was calculated as the difference between total binding and the binding measured in the presence of 100 fold excess of unlabeled ligand. Non-specific binding was less than $15 \%$.

Binding of $[\alpha-32 \mathrm{P}]$ GTP to Nitrocelluiose Blots -. The procedure was carried out as described by Bhullar and Haslam (16). Aliquots of samples were subjected to SDS/PAGE electrophoresis in $128 \mathrm{gels}$ and the resolved polypeptides transferred to nitrocellulose by electroblotting as described by Towbin et al. (17). Nitrocellulose blots were then incubated with 1 uCi of $\left[\alpha-32_{\mathrm{P}}\right]$ GTP for 1 hour at room temperature in buffer containing $50 \mathrm{mM}$ Tris$\mathrm{HCl}, 0.38$ tween $20,1 \mathrm{mM} \mathrm{MgCl} 2$ and $1 \mathrm{mM}$ EGTA $\mathrm{pH} 7.5$, dried and bound ${ }^{35} \mathrm{P}$ was detected by autoradiography $\left(24-72\right.$ hours at $\left.-80^{\circ} \mathrm{C}\right)$. Specific binding was 
determined by preincubation of the blots with GTP, GTPYS or ATP in buffer for 10 minutes at $30^{\circ} \mathrm{C}$, then $1 \mathrm{uCi}\left[\alpha-{ }^{32} \mathrm{P}\right] \mathrm{GTP}$ was added and the blots treated as above.

Other Methods - - Protein was determined as described by Bradford et al. (18). Bovine serum albumin was used as a standard.

Results - Separation of GIP-Binding Activity from Phospholipase C Activity Platelet high speed supernatant (total protein 1 gram) was applied to a $Q$ Sepharose column $(2.5 \times 18 \mathrm{~cm})$. The column was washed with $20 \mathrm{mM}$ Tris-maleate containing $100 \mathrm{mM} \mathrm{NaCl}, 1 \mathrm{mM}$ EGTA and $0.1 \mathrm{mM}$ dithiothreitol $\mathrm{pH} 7.6$. PLC and GTPrs-binding activities were eluted from the column with a linear salt gradient (100 mM to $500 \mathrm{mM}$ ). PLC and GTP S-binding activities coeluted as a single peak at approximately $250 \mathrm{mM} \mathrm{NaCl}$ (data not shown). The active fractions were pooled, concentrated by Amicon centricon (PM 10 ) and dialyzed against $20 \mathrm{mM}$ Tris-HCl containing $100 \mathrm{mM} \mathrm{NaCl} 1 \mathrm{mM}$ EGTA and $0.1 \mathrm{mM}$ dithiothreitol pH 7.6 (Buffer A). The enzyme preparation was then applied to a heparin-agarose column preequilibrated with Buffer A. PLC activity eluted as a single peak at $300 \mathrm{mM} \mathrm{NaCl}$ (fig. 1). However, GTPrs-binding activity was fractionated into two peaks, GI and GII. GI was found in the breakthrough of the heparin-agarose column, while GII co-eluted with phospholipase C activity (fig. 1).

To separate PLC activity from GTP S-binding activity, peak GII fractions the from heparin-agarose column were pooled, dialyzed overnight against

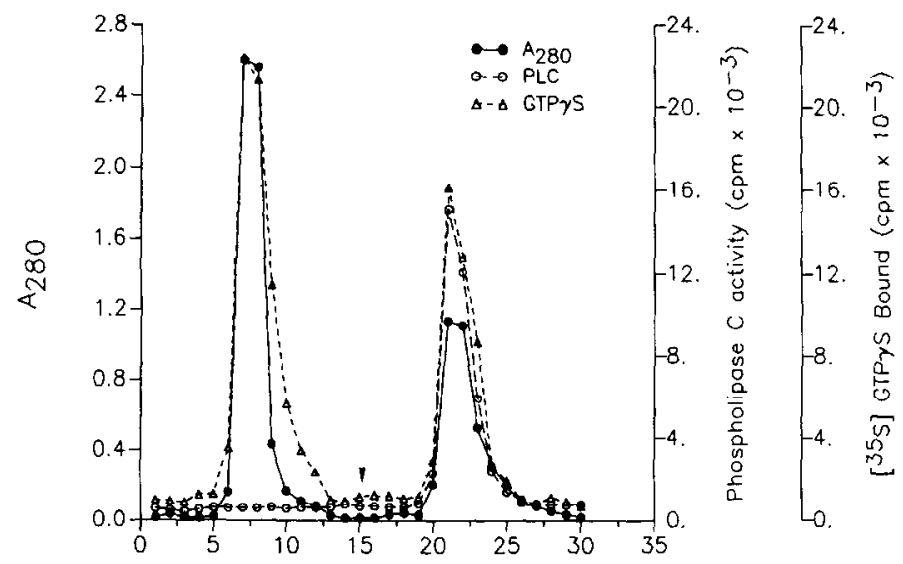

Fraction Number

Figure 1. Heparin-agarose chromatography of cytosol from human platelets Cytosol was applied to a heparin-agarose column. The column was washed with $20 \mathrm{mM}$ Tris-HCl buffer $\mathrm{pH} 7.6,100 \mathrm{mM} \mathrm{NaCl}, 1 \mathrm{mM}$ EGTA, $0.1 \mathrm{mM}$ dithiothreitol and then eluted with $300 \mathrm{mM} \mathrm{NaCl}$ as described under Experimental Procedures. The flow rate was $1 \mathrm{ml} / \mathrm{min}$ and $6 \mathrm{ml}$ fractions were collected. Phospholipase $C$ was assayed with $\mathrm{PI} / \mathrm{PE} / \mathrm{PS}$ vesicles in the presence of $1 \mathrm{mM} \mathrm{Ca}{ }^{2+}$. GTP $\gamma_{S}$ binding was assayed as described under Experimental Procedures. $(O-O)$, phospholipase $C$ activity; $(\Delta-\Delta)$, GTP $\gamma_{S}-$ binding activity; (O- $)$, absorbance at $280 \mathrm{~nm}$. 


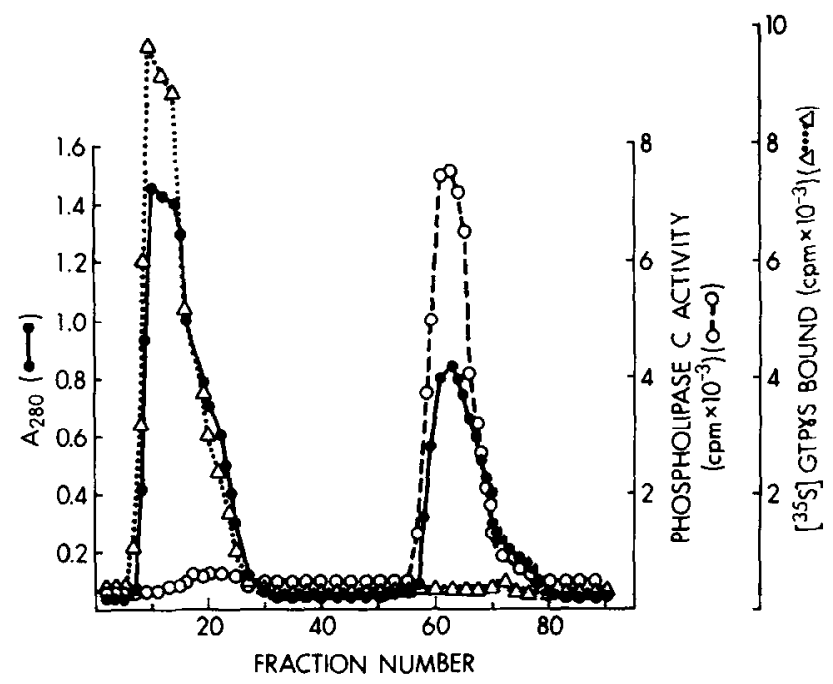

Figure 2. Separation of phospholipase C activity from GTP/S-binding activity by hepaxin-agarose column chromatography in the presence of $0.5 \%$ cholate. Fractions containing phospholipase $C$ activity from the heparin-agarose column. (fig. 1) were dialyzed against $20 \mathrm{mM}$ Tris-HCl buffer pH $7.6100 \mathrm{mM} \mathrm{NaCl}, 1 \mathrm{mM}$ EGTA, $0.1 \mathrm{mM}$ dithiothreitol plus 0.58 cholate and then applied to a second heparin-agarose column which had been equilibrated with dialysis buffer. The column was then washed with equilibration buffer and phospholipase $C$ activity eluted with $300 \mathrm{MM} \mathrm{NaCl}$. Phospholipase $C$ activity was assayed as described in the legend to figure $1 .\left(\mathrm{O}^{-}+\mathrm{O}\right)$, phospholipase $\mathrm{C}$ activity; $(\Delta-\Delta)$, GTP $\gamma_{\mathrm{S}}$ -

binding activity; (O-O), absorbance at $280 \mathrm{~mm}$.

Buffer A, which also contained 0.58 sodium cholate, (Buffer B), and then applied to a second heparin-agarose column, which had been preequilibrated with Buffer $B$. As shown in figure 2, enzyme activities were fractionated into two peaks (fractions I and II). GTP S-binding activity was recovered in the breakthrough (GII-fraction I) while PLC activity was eluted by $300 \mathrm{mM} \mathrm{NaC1}$ (GII-fraction II).

Identification of Platelet Soluble GTP S-Binding Proteins - ADP ribosylation of the high speed supernatant by pertussis toxin plus [ $\left.{ }^{32} P\right]$ NAD showed a single band of radioactivity with $\mathrm{Mr}$ of 41,000 daltons (data not shown). This protein is most likely the alpha subunit of $\mathrm{Gi}$, which is 41,000 daltons and is the major pertussis toxin substrate in platelets (19). In an attempt to identify the other GTPrS-binding proteins in the high speed supernatant and column fractions, nitrocellulose blots of these protein fractions were incubated with $\left[\alpha-{ }^{32} \mathrm{P}\right]$ GTP as described by Bhullar and Haslam (16). Western blots of high speed supernatant from human platelets contained 3-4 GTP-binding proteins with molecular weights between $29 \mathrm{kDa}$ and $24 \mathrm{kDa}$ (fig. 3, lane A).

The first peak of GTP-binding activity that was eluted from the first heparin-agarose column (peak GI, fig. 1) contained multiple GTP-binding bands similar to those found in the high speed supernatant (fig. 3, lane b). The 


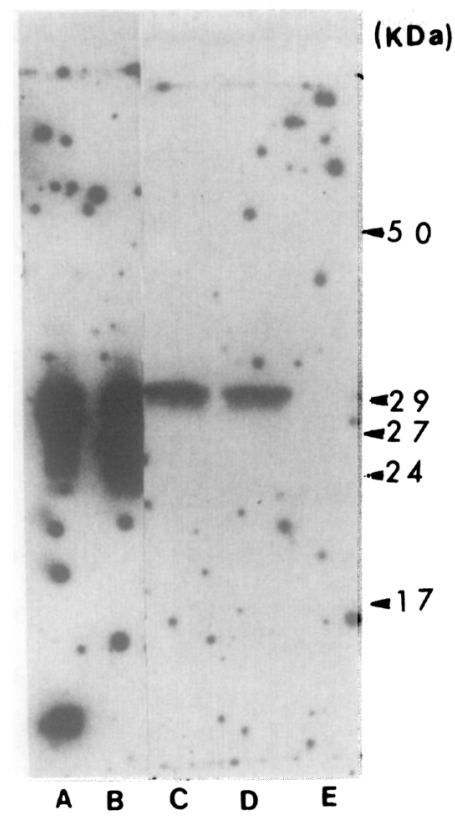

Figure 3. Detection of GTP-binding proteins on nitrocellulose blots.

Proteins from the high speed supernatant (100 ug) and fractions from the heparin-agarose columns $(100 \mathrm{ug})$ were electrophoresed and blotted on nitrocellulose. The blots were incubated with $1 \mathrm{nM}\left[\alpha-{ }^{32} \mathrm{P}\right]$ GTP and $2 \mathrm{mM}$ $\mathrm{MgCl}_{2}$. Lane $A$ is cytosol; lane $B$ and $C$ are $G I$ and GII, respectively from the first heparin-agarose column (fig. 1); lane D and $E$ are fractions from the second heparin-agarose column (fig. 2) containing GTP/S-binding activity and phospholipase $C$ activity, respectively.

second peak of GTP-binding activity (peak GII), which co-eluated with PLC activity, contained a single GTP-binding band of molecular weight 29,000 (G29) (fig. 3, lane c). In addition, since ADP-ribosylation of peak GII by pertussis toxin plus $\left[{ }^{32} \mathrm{P}\right]$ NAD did not give any band of radioactivity (data not shown), these fractions do not contain Gi. Rechromatography of peak GII on heparin-agarose in the presence of sodium cholate (fig. 2) resulted in recovery of 629 in the breakthrough fractions (peak GII-fraction I) (fig. 3 , lane d). No GTP-binding bands were found in peak GII-fraction II from this column, which contained PLC activity (fig. 3, lane e).

Stinulation of Phospholipase $C$ activity by CTPYS We next examined the effects of GTPrS on PLC activity in the platelet high speed supernatant and in fractions from heparin-agarose in the absence (peak GII) and presence of sodium cholate (peak GII-fraction II). As we (14) and Deckmyn et al. (16) have previously observed, $\mathrm{PIP}_{2}$ but not PI breakdown by PLC in the high speed supernatant was significantly increased by the addition of GTPrS (Table I). Addition of GTPrS to the PLC partially purified by Q Sepharose and heparinagarose chromatography (Peak GII) also significantly enhanced $\mathrm{PIP}_{2}$, but not PI hydrolysis. Rechromatography of this activity on heparin-agarose, in the presence of sodium cholate, resulted in loss of responsiveness of the PLC 
Table I Reconstitution of GTP S Stimulated PIP 2 Hydrolysis by Cytosolic PLC

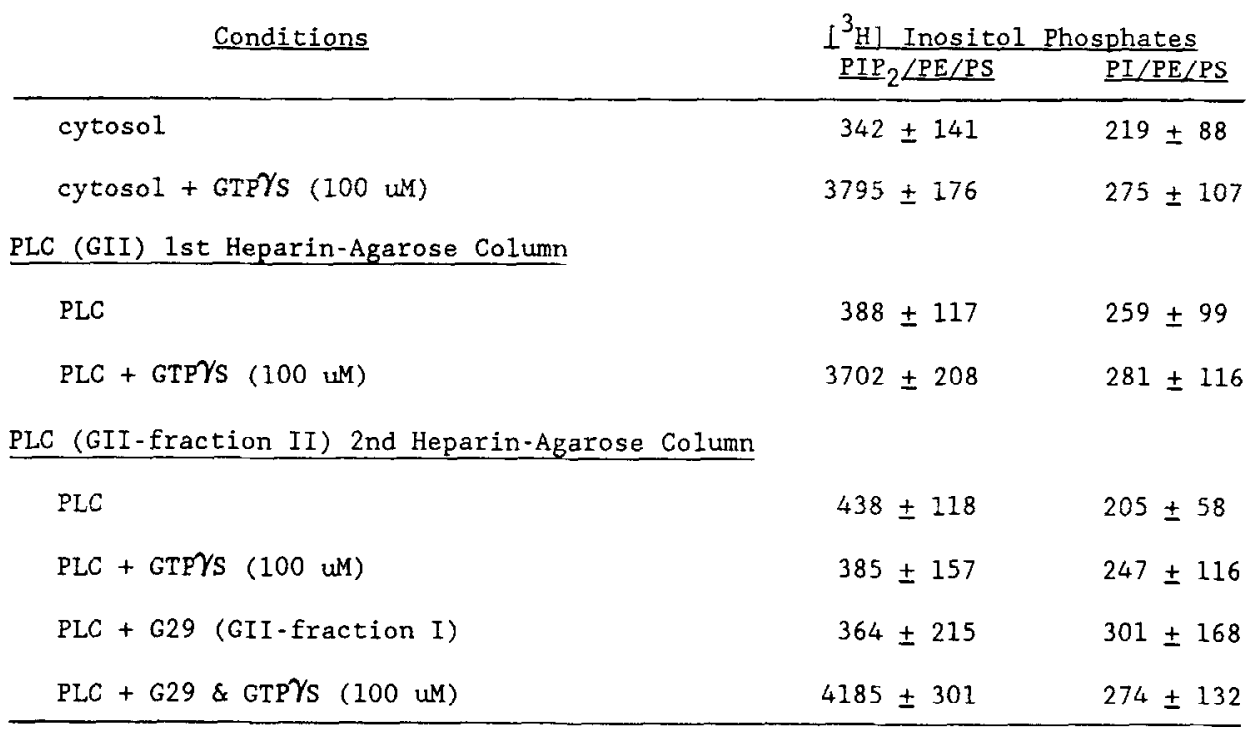

Phospholipase $C$ activity was measured using $P I P_{2} / P E / P S$ or $P I / P E / P S$ vesicles (20 $\times 10^{3} \mathrm{cpm} /$ assay) in the presence of $1 \mathrm{uM} \mathrm{Ca}{ }^{+4}$ as described in Experimental Procedures. PLC (GII) is the fraction containing PLC activity from the first heparin-agarose colunn (fig. 1). PLC (G-II-fraction II) is the fraction containing PLC activity from second heparin-agarose column (fig. 2). G29 (GII-fraction I) is GTP-binding activicy from second heparin agarose column (fig. 2). The reaction was stopped after 5 minutes and inositol phosphates quantitated as described under Experimental Procedures. Results are expressed as the mean $\pm S D$ from three separate experiments.

activity (GII-fraction II) to GTPYS. GTP-dependent PIP hydrolysis could be fully restored by addition of the G29-containing fraction (GII-fraction I) to the PLC.

Discussion - The data in this paper demonstrate that the high speed supernatant from human platelets contains 3-4 specific GTP-binding proteins with molecular weights ranging from $29 \mathrm{kDa}$ to $24 \mathrm{kDa}$. Similar results were found by Lapetina and Reep (20) and Bhullar and Haslam (16). We have further separated the GTPrS-binding into two fractions, GI and GII, by heparin-agarose chromatography in the absence of detergent. While GI contained multiple GTPbinding proteins, GII was found to contain a single GTP-binding protein (G29) with molecular weight $29 \mathrm{kDa}$ which co-chromatographed with PLC activity.

We have also demonstrated that purification of the cytosolic PLC by heparin-agarose chromatography in the presence of detergent resulted in the loss of GTPrS dependent stimulation of PIP 2 hydrolysis. GTPrS-responsiveness was restored when fractions from the heparin-agarose column containing PLC activity were reconstituted with fractions containing GTPrs-binding activity i.e. G29. These results clearly indicate that platelet cytosol contains GTPYS-binding activity and that GTP-binding G protein(s), possibly G29, 
regulates cytosolic PLC activity. We are presently purifying the GTP-binding protein in peak GII-fraction I responsible for GTP $\gamma$ S dependent stimulation of $\mathrm{PIP}_{2}$ by the cytsolic PLC.

\section{References}

1. Taylor, S.J. and Exton, J.H. (1987) Biochemical J. 248, 791-799

2. Litosch, I and Fain, J.N. (1985) J. Biol Chem. 260,16052-16055

3. Cockeroft, S. and Gomperts, B.D. (1985) Nature (London) 314, 534-536

4. Baldassare, J.J., Henderson, P.A. and Fisher, G.J. Submitted to J. Biol. Chem.

5. O'Rourke, F., Zavorco, G.B., Smith, L.H, and Feinstein, M.B. (1987) FEBS Lett. 214, 176-180

6. Brass, L.F., Laposata, M., Banga, H.S. and Rittenhouse, S.E. (1986) J. Bio1. Chem. 261, 16838-16847

7. Haslam, R.J. and Davidson, M.M.L. (1984) J. Receptor Res. 4, 605-629

8. Haslam, R.J. and Davidson, M.M.L. (1984) FEBS Lett. 174, 90-95

9. Baldassare, J.J. and Fisher, G.J. (1986) J. Bio1. Chem 261, 11942-11944

10. Hrobolich, J.K., Culty, M. and Haslam, R.J. (1987) Biochem J. 243, $457-$ 465

11. Deckmyn, H. Tu, S.M. and Majerus, P.W. (1986) J. Biol. Chem. 261, 16553 16558

12. Banno, Y., Nakashima, S., Tohmatsu, T., Nozawa, Y. and Lapetina, E.G. (1986) Biochem. Biophys. Res. Comm. 140, 728-734

13. Jolles, J., Swiens, H., Dekkeu, A., Wertz, K.W.A. and Gispen, W.H. (1981) Biochem J. 194, 282-291

14. Raaflaub, J. (1960) Methods Biochem. Anal. 3, 301-325.

15. Northup, J. K., Smige1, M.D. and Gilman, A.G. (1982) J. Biol. Chem. 257, $11416-11423$

16. Bhullar, R. P. and Haslam, R.J. (1987) Biochem J. (1987) 245, 617-620

17. Towbin, H., Staehelin, T. and Gordon, J. (1979) Proc. Nat1. Acad. Sci. USA $76,4350-4354$

18. Bradford, M.M. (1976) Anal. Biochem. 72, $248-254$

19. Gilman, A.G. (1987) Ann Rev. Biochem. 56, 615-649

20. Lapetina, E.G. and Reep, B.R. (1987) Proc. Natl. Acad. Sci. USA 84, 2261. -2265 